\title{
EVALUATION OF RESULTS IN INTRAMEDULLARY FIXATION OF SUBTROCHANTERIC FRACTURE OF FEMUR WITH PROXIMAL FEMORAL NAILING (AO TYPE OF DESIGN)
}

\author{
D. Nitin Reddy' ${ }^{1}$ A. Anand ${ }^{2}$, Y. Raviteja ${ }^{3}$ \\ 1 Post Graduate, Department of Orthopaedics, Konaseema Institute of Medical College, Amalapuram. \\ 2 Post Graduate, Department of Orthopaedics, Konaseema Institute of Medical College, Amalapuram. \\ ${ }^{3}$ Senior Resident, Department of Orthopaedics, Konaseema Institute of Medical College, Amalapuram.
}

\begin{abstract}
BACKGROUND

Among the femoral shaft injuries, upper femoral fractures present a peculiar problem of securing effective neutralization of deforming forces. The mechanical stresses at this level are very high, as they occur at the junction between the trabecular and cortical zone and also because of the deforming forces due to peculiar muscle insertion to the proximal and distal fragments. The present study was conducted to assess the utility and effectiveness of Proximal Femoral Nail evolved by A0-ASIF in 1997, for various types of upper femoral fractures.
\end{abstract}

\section{MATERIAL AND METHOD}

The present study consists of the patients admitted to Orthopaedic Units of KIMS Hospital, between June 2012 and July 2014; 1267 fracture cases were treated in Department of Orthopaedics, Konaseema Institute of Medical Sciences, Amalapuram, during this period. Of these 264 patients were admitted for femoral fractures. Of the 264 femoral fractures, 18 patients above the age of 20 years with subtrochanteric fractures were included in this study.

\section{RESULT}

Reduction was good in $72.2 \%$ (13) of the cases. Acceptable reduction was achieved in $3(16.6 \%)$ patients. Poor reduction was noted in $2(11.1 \%)$ patients. One of them were of elderly age group and had poor outcome at final follow-up.

\section{SUMMARY AND CONCLUSION}

From this sample study, we conclude that Proximal Femoral Nail is a good implant for the treatment of subtrochanteric fractures of femur provided optimal reduction of the fracture and good positioning of the nail and screws are achieved.

\section{KEYWORD}

Intramedullary Fixation, Subtrochanteric Fracture, Proximal Femoral Nailing.

HOW TO CITE THIS ARTICLE: Reddy DN, Anand A, Raviteja Y. Evaluation of results in intramedullary fixation of subtrochanteric fracture of femur with proximal femoral nailing (AO type of design). J. Evolution Med. Dent. Sci. 2016;5(64):4547-4551, DOI: $10.14260 /$ jemds/2016/1038

\section{INTRODUCTION}

Civilization and modernization has brought certain problems along with its own benefits to the citizens of the world over. Fast lifestyles, rapid and high speed transportation, risky infrastructural projects and modern commando warfare activities have brought in with them morbidity and mortality due to trauma in general and fractures of femur in particular.

Among the femoral shaft injuries upper femoral fractures present a peculiar problem of securing effective neutralization of deforming forces. The mechanical stresses at this level are very high, as they occur at the junction between the trabecular and cortical zone and also because of the deforming forces due to peculiar muscle insertion to the proximal and distal fragments. These factors have made subtrochanteric fractures demand special consideration in orthopaedic trauma, because defective union of this fracture can lead to high disability levels for an individual and thereby loss of valuable man days.

Financial or Other, Competing Interest: None.

Submission 28-04-2016, Peer Review 26-05-2016,

Acceptance 03-06-2016, Published 11-08-2016.

Corresponding Author:

Dr. D. Nitin Reddy,

Post Graduate,

Department of Orthopaedics,

Konaseema Institute of Medical College,

Amalapuram.

E-mail: anand_kims@yahoo.co.in

DOI: $10.14260 /$ jemds/2016/1038
Orthopaedic fraternity is always on the lookout for an effective and suitable method to treat the upper femoral fractures in the best possible way. In this process surgical management of these fractures and the surgical implants used have also gone through an array of changes in their procedures and designs. Various upper femoral devices like dynamic condylar screw, dynamic hip screw with barrel plate, gamma nail, proximal femoral nail, etc. are being used by various centres and each centre claims reasonably satisfactory results with each type of device. The present study was conducted to assess the utility and effectiveness of Proximal Femoral Nail evolved by AO-ASIF in 1997 for various types of upper femoral fractures.

\section{MATERIAL AND METHODS}

The present study consists of the patients admitted to Orthopaedic Units of KIMS Hospital between June 2012 and July 2014; 1267 fracture cases were treated in Department of Orthopaedics, Konaseema Institute of Medical Sciences, Amalapuram, during this period. Of these 264 patients were admitted for femoral fractures. Of the 264 femoral fractures, 18 patients above the age of 20 years with subtrochanteric fractures were included in this study. Among the 18 patients, 9 were females and 9 were males. The mean age of presentation was 65.61 years. The most common mechanism of injury was a simple fall in females and high velocity injuries (Fall from height, Road traffic accidents) in males. 
Seinsheimer type IIIA fracture pattern was the most common type to be seen. Pathological fractures and subtrochanteric fractures of femur with ipsilateral femoral shaft or neck fractures were excluded from the study.

Upon arrival the patients were assessed clinically and were stabilized haemodynamically. They were then subjected for radiographs of Pelvis with both hips antero-posterior view and full length thigh antero-posterior and lateral views. Following radiographs patients were admitted to orthopaedic wards and were maintained on skin traction over a BohlerBraun frame till surgery to overcome muscle spasm. Appropriate blood investigations were done and surgical fitness was obtained. All the patients were operated on a fracture table in supine position under image intensifier control using standard techniques. Patients were discharged on the tenth post-operative day following suture removal, and their post-operative period was uneventful.

Patients were assessed clinically and radiologically on the $2^{\text {nd }}$ post-operative day, at 6 weeks, 3 months and then between 6 months to 1 year depending upon the fracture union. These findings are documented according to a protocol that was developed. Healing was judged by both clinical (Pain and motion at fracture site and radiological (Bridging callus filling the fracture site or trabeculations across the fracture site) criteria and functional outcome was reviewed according to the Harris Hip score (Modified).

\section{OBSERVATIONS}

\begin{tabular}{|c|c|c|c|c|c|c|}
\hline $\begin{array}{l}\text { Total No. of } \\
\text { Fractures }\end{array}$ & \multicolumn{4}{|c|}{ Lower Limb Fracture } & $\begin{array}{c}\text { Upper } \\
\text { Limb } \\
\text { Fractures }\end{array}$ & $\begin{array}{c}\text { Other } \\
\text { Fractures }\end{array}$ \\
\hline \multirow{7}{*}{1267} & \multicolumn{4}{|c|}{583} & \multirow{7}{*}{349} & \multirow{7}{*}{335} \\
\hline & \multicolumn{3}{|c|}{ Femoral Fractures } & Other Fractures & & \\
\hline & \multicolumn{3}{|c|}{264} & \multirow{5}{*}{319} & & \\
\hline & Upper Femor & ractures & Other Fractures & & & \\
\hline & \multicolumn{2}{|c|}{216} & \multirow{3}{*}{48} & & & \\
\hline & $\begin{array}{l}\text { Subtrochanteric } \\
\text { Fractures }\end{array}$ & $\begin{array}{c}\text { Other } \\
\text { Fractures }\end{array}$ & & & & \\
\hline & 18 & 198 & & & & \\
\hline & ncidence of Fract & in Dept. o & thopaedics, KIMs & ween June 2012 & d July 2014 & \\
\hline
\end{tabular}

A total number of 1267 fractures were admitted in our department between June 2012 and July 2014. Of these 46\% (583) were lower limb fractures, 28\% (349) were upper limb fractures and $26 \%$ (335) were other factures that include spine, pelvis, etc. Of the lower limb fractures, $45.2 \%$ (264) were femoral fractures. Of the femoral fractures, $81.81 \%$ (216) were upper femoral fractures and subtrochanteric fractures account for $8.3 \%$ (18) of these fractures.

\begin{tabular}{|c|c|c|}
\hline $\begin{array}{c}\text { Age } \\
\text { Group }\end{array}$ & $\begin{array}{c}\text { Number of } \\
\text { Patients }\end{array}$ & Percentage \\
\hline $20-30$ & 1 & $5.5 \%$ \\
\hline $31-45$ & 1 & $5.5 \%$ \\
\hline $46-60$ & 2 & $11.1 \%$ \\
\hline$>61$ & 14 & $77.7 \%$ \\
\hline Total & $\mathbf{1 8}$ & $\mathbf{1 0 0 \%}$ \\
\hline \multicolumn{2}{|c|}{ Age of the Patient with Subtrochanteric Fractures } \\
\hline
\end{tabular}

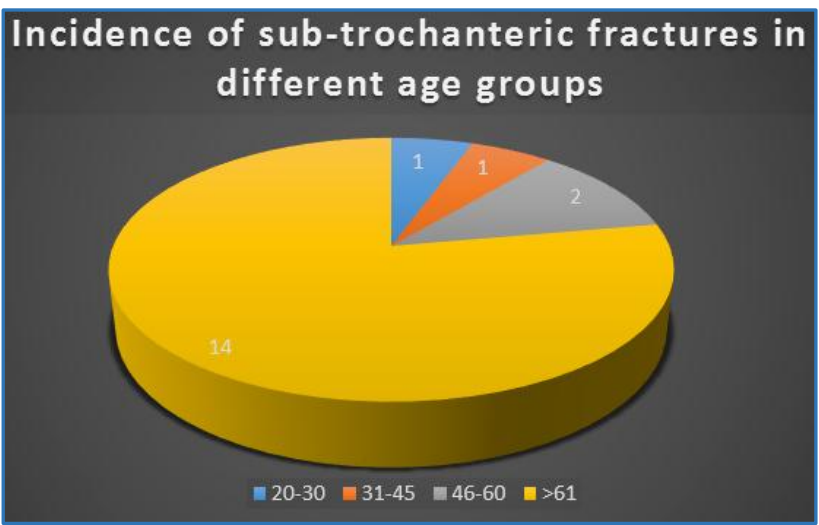

The youngest patient in our series is 30 years old and the oldest is 80 years. Maximum number of patients in this study are of elderly age group and the mean age is 65.61 years.

\begin{tabular}{|c|c|c|}
\hline Sex & Number of Patients & Percentage \\
\hline Male & 9 & $50 \%$ \\
\hline Female & 9 & $50 \%$ \\
\hline Total & $\mathbf{1 8}$ & $\mathbf{1 0 0} \%$ \\
\hline \multicolumn{2}{|c|}{ Sex and Type of Injury } \\
\hline
\end{tabular}

In the present study, it is seen that subtrochanteric fractures are equally proportionate in both females and males.

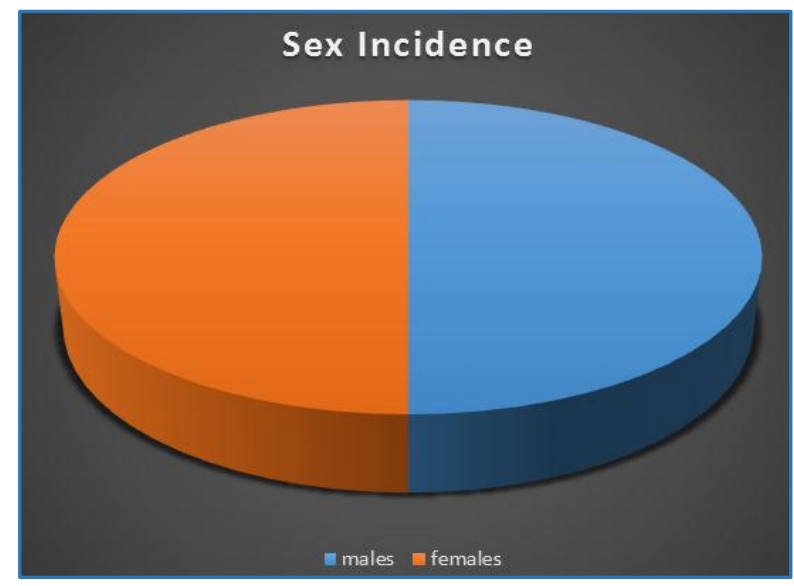

\begin{tabular}{|c|c|c|}
\hline Sex & High Velocity Injury & $\begin{array}{c}\text { Low Velocity Injury/ } \\
\text { Conventional Trauma }\end{array}$ \\
\hline Male & $7(78 \%)$ & $2(22 \%)$ \\
\hline Female & $1(11 \%)$ & $8(89 \%)$ \\
\hline Total & $\mathbf{8}$ & $\mathbf{1 0}$ \\
\hline
\end{tabular}




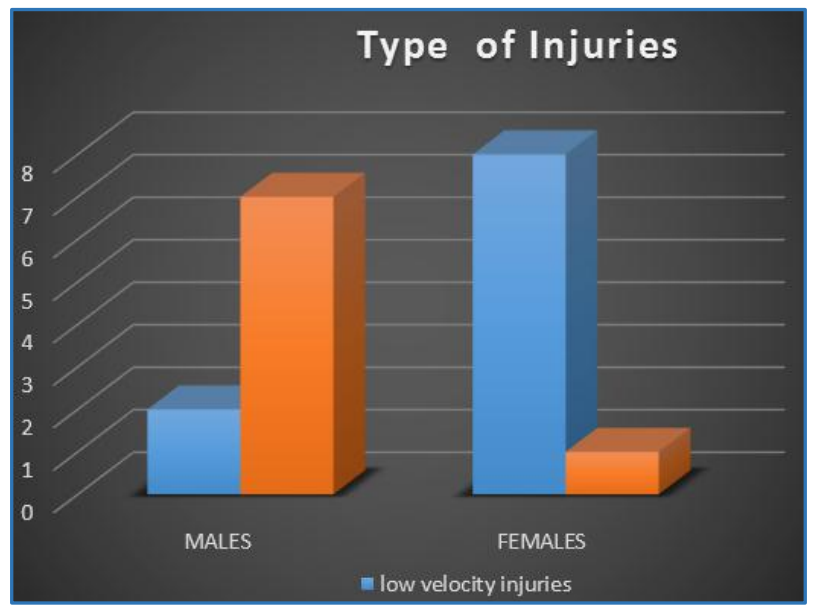

\begin{tabular}{|c|c|}
\hline \multirow{2}{*}{ Mean } & Present Series \\
\cline { 2 - 2 } & 6.6 Days \\
\hline \multicolumn{2}{|c|}{ Admission-Operation Interval } \\
\hline
\end{tabular}

The mean injury operation interval in the current series is 6.6 days. This increased interval is mainly due to uncontrolled pre-existing illness at the time of presentation.

\begin{tabular}{|c|c|c|c|c|c|c|c|}
\hline \multirow{3}{*}{ Percentage } & \multicolumn{3}{|c|}{ Type II } & \multicolumn{2}{c|}{ Type III } & Type & Type \\
\cline { 2 - 6 } & $\mathrm{A}$ & $\mathrm{B}$ & $\mathrm{C}$ & $\mathrm{A}$ & $\mathrm{B}$ & IV & V \\
\cline { 2 - 6 } & $0 \%$ & $0 \%$ & $16.6 \%$ & $44.4 \%$ & $5.5 \%$ & $27.7 \%$ & $5.5 \%$ \\
\hline Incidence Based on Seinsheimer's Classification \\
\hline
\end{tabular}

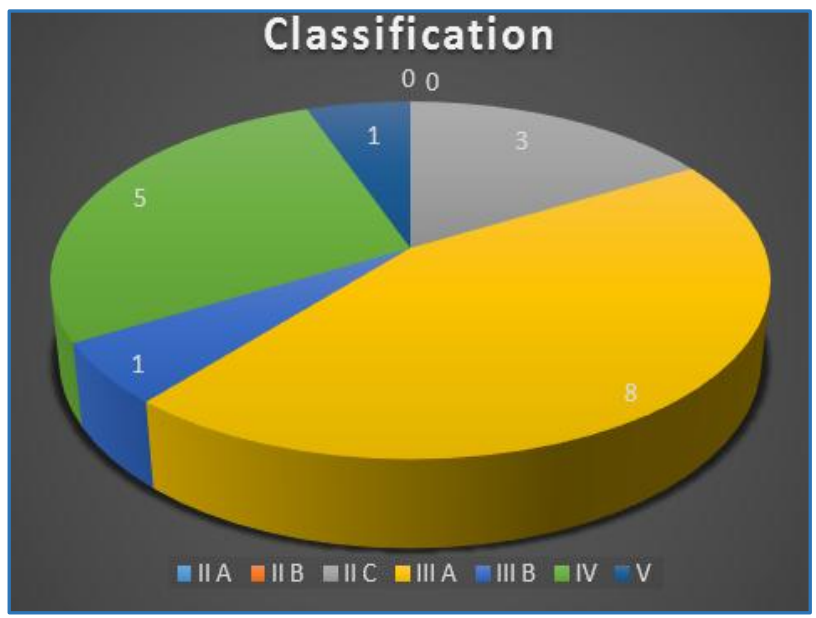

\begin{tabular}{|l|r|r|}
\hline \multirow{2}{*}{ Percentage } & Closed & Open \\
\cline { 2 - 3 } & $94.5 \%$ & $5.5 \%$ \\
\hline \multicolumn{3}{|c|}{ Type of Reduction } \\
\hline
\end{tabular}

Intraoperatively, reduction of the fracture was achieved through closed means in $94.5 \%$ (17) of cases. Open reduction was performed in only 1 patient who had high injury operation interval.

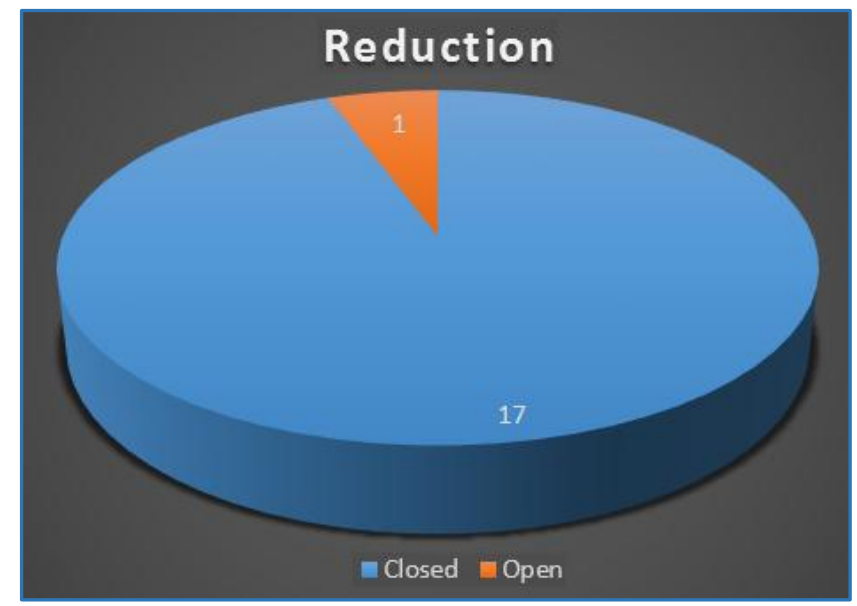

\begin{tabular}{|l|c|c|c|}
\hline \multirow{2}{*}{ Percentage } & Good & Acceptable & Poor \\
\cline { 2 - 4 } & $72.2 \%$ & $16.6 \%$ & $11.1 \%$ \\
\hline \multicolumn{4}{|c|}{ Result of Reduction } \\
\hline
\end{tabular}

Reduction was good in $72.2 \%$ (13) of the cases. Acceptable reduction was achieved in $3(16.6 \%)$ patients. Poor reduction was noted in $2(11.1 \%)$ patients. One of them were of elderly age group and had poor outcome at final follow-up.

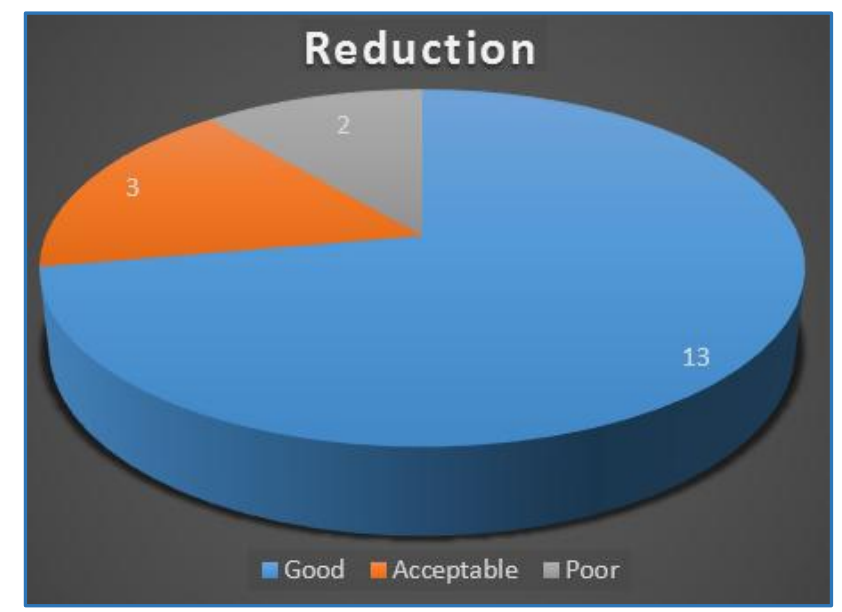

\begin{tabular}{|c|c|}
\hline \multirow{2}{*}{ Average Time for Union } & Present Study \\
\cline { 2 - 2 } & 3 Months \\
\hline \multicolumn{2}{|c|}{ Fracture Union } \\
\hline
\end{tabular}

\begin{tabular}{|c|c|c|}
\hline Sl. No. & Complication & Percentage \\
\hline 1. & Superficial infection & $5.5 \%$ \\
\hline 2. & Deep infection & 0 \\
\hline 3. & Cut out of screw & $5.5 \%$ \\
\hline 4. & Reverse 'Z' effect of hip screws & 0 \\
\hline 5. & 'Z' effect of hip screws & 0 \\
\hline 6. & Shaft fracture & 0 \\
\hline \multicolumn{3}{|c|}{ Complications } \\
\hline
\end{tabular}

In the present series, $5.5 \%$ (1) of cases had superficial infection and no deep infections were recorded. Cut of the antirotational screw was noted in 1 patient.

\begin{tabular}{|l|c|}
\hline \multirow{2}{*}{ Harris Hip Score } & Mean Score \\
\cline { 2 - 2 } & 83.9 \\
\hline \multicolumn{2}{|c|}{ Overall Result Based on Harris Hip Score } \\
\hline
\end{tabular}


In the current series, the mean Harris Hip score was 83.9 and it was ranging from 100-26.

Overall result based on the age group of the patient.

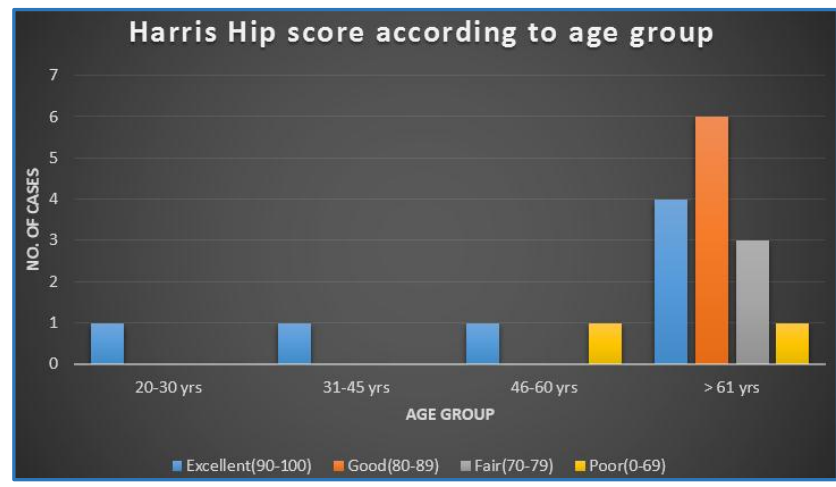

In this series, all the patients between 20-45 years had excellent result irrespective of the type of fracture. Two patients above 45 years had poor results and remaining $50 \%$ had good-to-fair results.

\section{DISCUSSION}

Fractures of the long bones are a major social and economic problem. Of the long bone fractures, subtrochanteric fractures of the femur have peculiar anatomic and mechanical characteristics, which pose problems in their management. Closed intramedullary devices have a mechanical advantage that effectively addresses these factors. The benefit of minimal surgical exposure, more efficient load transfer through calcar femorale and decreased tensile strain on the implant because of its shorter lever arm makes proximal Femoral Nail a good choice of implant for subtrochanteric fractures of the femur. Various studies have considered Proximal Femoral Nail as an acceptable minimally invasive implant for Subtrochanteric fracture.

The incidence of subtrochanteric fracture is relatively low. In our study, 18 subtrochanteric fractures accounted for $8.3 \%$ of all proximal femoral fractures. In other studies, $7 \%-34 \%$ of all femur fractures occurred in the subtrochanteric region. The incidence of subtrochanteric fracture is relatively low. Most of our patients are of the elderly age group, the average age being 65.6 years. This is lower compared to that quoted by other authors in literature, Boldin et al ${ }^{1} 73$ yrs., I.B. Schipper series. ${ }^{2}$ 82.2 years. The ratio between males and females was found to be 1:1, whereas female preponderance was reported by Boldin et al (70\%) and I.B. Schipper (82\%). Almost 55.5\% of the subtrochanteric fractures involved the right femur in this series as compared to 52\% in I.B. Schipper series and $44.5 \%$ involved the left as compared to $48 \%$ in I.B. Schipper series.

In $55.5 \%$ of patients, fracture is a result of trivial fall and majority of them are elderly age group patients, especially females. High velocity injuries like road traffic accidents and fall from heights accounted for $44.5 \%$ of these fractures and most of them were males. In W.M. GADEGONE's series, 75\% of the fractures were due to domestic falls and this can be explained by the higher mean age group of the patients in this study. Fractures were classified according to Seinsheimer's classification and type III A fracture pattern constituted the highest percentage $44.4 \% .^{(3)}$ of all fracture patterns. Seinsheimer in his original study also noted high incidence of type III A fracture pattern (38.29\%) than other fracture patterns. Admission-operation interval in our study varied from 3-11 days. Mean interval is high in our series. It is 6.6 days, which is more when compared to I.B. Schipper's series where it was 2 days. Most of the patients with delayed injuryoperation interval had pre-existing uncontrolled medical problems. These medical comorbidities, especially in elderly age group patients with associated degenerative joint disease of the knee significantly affected their final functional outcome. Intraoperatively, fracture reduction has achieved by closed means in $94.4 \% .{ }^{(4)}$ of patients and 1 patient with delayed injury -operation interval required open reduction. The result of the reduction was considered good in $72.2 \%$.(5) of the patients and

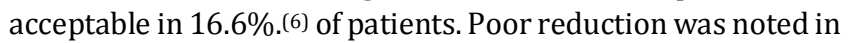
$11.1 \%$.(7) of patients and it was associated with poor outcome. In I.B. Schipper's series reduction was good to acceptable in $96.2 \%$ of their patients and poor reduction was seen only in $2.9 \%$ of their patients. Preoperatively, prophylactic antibiotic was given intravenously 1 hour before surgery. In all postoperative patients three days of prophylactic intravenous $3^{\text {rd }}$ generation cephalosporins were given. Out of 18 patients in this study, one patient had superficial infection (5.5\%) and this settled with parenteral antibiotics. I.B. Schipper noted $4.1 \%$ superficial infections and $2.5 \%$ deep infections. We did not encounter any deep infections in our series. In all geriatric patients and post-menopausal women supplementation with vitamin D3 and calcium was done. Mobilisation and physiotherapy with quadriceps strengthening exercises were encouraged prior to weight bearing. Cut out of hip screw was noted in 1 patient (5.5\%) and it was following a fall in the postoperative period; $6 \%$ of patients in I.B. Schipper's series had this problem. The average time for radiological union is 3 months in the present study, whereas in I.B. Schipper series, it was approximately 4 months; $66.66 \%$.8) of the patients in our series had no or slight pain that did not affect their activities. Only 1 patient who had cut out of the anti-rotational screw had severe pain that restricted her activity significantly; $77.7 \%$ of these patients had no or slight limp; $44.4 \%$. $^{(8)}$ of the patients mobilized without any walking aids. Cane was required for long walks in $38.8 \%$.(9) of patients and most of the time in $11.1 \%$.(2) $^{(2)}$ of patients. Only one patient required crutch for mobilization. Difficulty squatting and sitting cross legged noted in 55.5\%.(10) of patients. Most of these patients were of geriatric age group, who had associated degenerative disease of the knee. Limb length discrepancy was noted in 2 patients, of which 1 of them had shortening of more than $2 \mathrm{cms}$ for which shoe rise was given. They were patients with Seinsheimer's type IV and type $\mathrm{V}$ fracture patterns. Final outcome was excellent-to-good in $72.2 \%$.(5) of patients. It was fair in $16.6 \%$.(7) of patients and poor in $11.1 \% .6)$ of patients. Younger age group patients irrespective of their fracture pattern had excellent outcome in our series. Most of the poor results were seen in the elderly age group patients with associated Osteoarthritis of the knee. The mean Harris Hip score in our series is 83.9, which was higher than I.B. Schipper series where the mean was 77.6.

\section{SUMMARY AND CONCLUSION}

The incidence of subtrochanteric fractures of the femur is on the raise, because of fast and high speed automobiles and modern lifestyles and increased life expectancy of the elderly age group patients. The deforming forces, high mechanical stresses and morbidity of the fractures in this region have always challenged the ingenuity and skills of the orthopaedic 
surgeon. Various devices have evolved in an attempt to effectively neutralize these forces. Closed insertion technique, shorter lever arm decreasing the tensile strain on the implant and increased purchase of the proximal fragment are the added advantages of Cephalomedullary nails over other fixation devices in subtrochanteric fractures. This study has been conducted to analyse the results of subtrochanteric fractures treated with this Proximal Femoral Nail-AO Type.

In our series of 18 cases of subtrochanteric fractures treated with Proximal Femoral Nail, 13 patients had Excellentto-good outcome at their final follow-up. Poor outcome was seen in 2 patients; 1 of these 2 patients had poor reduction intraoperatively. All of these patients belonged to geriatric age group who had associated degenerative joint disease of the knee affecting the final functional outcome. The mean Harris Hip score at their final follow-up was 83.9, which is comparable to international publications in the literature.

From this sample study, we conclude that Proximal Femoral Nail is a good implant for the treatment of subtrochanteric fractures of femur provided optimal reduction of the fracture and good positioning of the nail and screws are achieved.

\section{REFERENCES}

1. Boldin C, Seibert FJ, Fankhauser F, et al. The proximal femoral nail (PFN) - a minimal invasive treatment of unstable proximal femoral fractures. Acta Orthop Scand 2003;74(1):53-8.
2. Schipper IB, Steyerberg EW, Castelein RM, et al. Treatment of unstable trochanteric fractures. JBJS 2004;86B:86-94.

3. Evans EM. The treatment of trochanteric fractures of the femur. J Bone Jt Surg 1949;31-B:190-203.

4. Zickel RE. An intramedullary fixation device for the proximal part of the femur. Nine years' experience. J Bone and Joint Surg 1976;58(6):866-72.

5. Distefano VJ, Nixon JE, Klein KS. Stable fixation of the difficult subtrochanteric fracture. J Trauma 1972;12(12):1066-70.

6. Sarmiento, Augusto. Functional bracing of tibial and femoral shaft fractures. Clin Orthop 1972;82:2-13.

7. Seinsheimer F. Subtrochanteric fractures of the femur. J Bone Jt Surg 1978;60(3):300-6.

8. Aronoff PM, Davis PM, Wickstrom JK. Intramedullary nail fixation as treatment of subtrochanteric fractures of the femur. J Trauma 1971;11:637-50.

9. Cleveland $\mathrm{M}$, Bosworth DM, Thompson FR. Intertrochanteric fractures of the femur: a survey of treatment in traction and by internal fixation. J Bone \& Joint Surg 1947;29(4):1049-67.

10. Boyd HB, Griffin LL. Classification and treatment of trochanteric fractures. Arch Surgery 1949;58(6):853-66. 